\title{
PRIMEIRO REGISTRO DE EPIDEMIAS CAUSADAS PELO VÍRUS OROPOUCHE NOS ESTADOS DO MARANHÁO E GOIÁS, BRASIL.
}

\author{
Pedro Fernando da Costa VASCONCELOS (1), Jorge Fernando Soares TrAVASSOS DA ROSA (1), Sueli Corrêa \\ GUERREIRo (1), Nicolas DÉgAller (2), Elizabeth Sabé TRAVASSOS DA ROSA (1) \& Amelia Paes de Andrade \\ TRAVASSOS DA ROSA (1)
}

\begin{abstract}
RESUMO
Os autores descrevem a ocorrência de epidemias causadas pelo virus Oropouche (ORO) nos Estados do Maranhão (MA) e Goiás (GO) em 1988. 36 amostras de vírus foram obtidas a partir da inoculação do sangue de 120 pacientes em camundongos recém nascidos. A doença foi caracterizada por febre, cefaléia, dores musculares, articulares, fotofobia, dor retro ocular, náuseas e tontura. 128 das 197 pessoas examinadas em Porto Franco, MA, tinham anticorpos inibidores da hemaglutinação (IH) para o agente e, em 106 foram detectados anticorpos IgM por MAC ELISA. Todos os grupos etários foram infectados, embora a incidência tenha sido mais elevada entre aqueles com 10 a 19 anos de idade. Quanto ao sexo, a infecção ocorreu igualmente em ambos os sexos. Recorrência dos sintomas foi observada em $56 \%$ dos casos positivos estudados. A inoculação em camundongos Swiss recém nascidos de 3.624 Culicoides paraensis (Ceratopogonidae) e 1.970 Culex (Culex) quinquefasciatus (Culicidae), coletados em Porto Franco-MA, resultou em um único isolamento do vírus ORO a partir dos Culicoides. Essa é a primeira descrição de casos confirmados de infecção pelo vírus Oropouche nos Estados do Maranhão e Goiás, Brasil.
\end{abstract}

UNITERMOS: Arbovírus; Oropouche; Doença humana; Isolamentos; Culicoides paraensis

\section{INTRODUÇÃO}

A febre do Oropouche (ORO) constitui em termos de Saúde Pública, uma das arboviroses mais importantes na Amazônia brasileira. O vírus ORO antigenicamente está incluído no sorogrupo Simbú da classificação de CASALS' e, taxonomicamente integra o gênero Bunyavirus, da família Bunyaviridae, segundo BISHOP \& SHOPE2. O ORO foi isolado originalmente em 1955, a partir do sangue de um paciente febril em Port of Spain-Trinidad?. Em 1960, obtevese seu isolamento pela primeira vez no Brasil, do sangue de uma preguiça (Bradypus tridacty- lus) capturada na rodovia Belém-Brasília ${ }^{4}$, às proximidades de Belém. No ano seguinte, ocorreu uma epidemia na capital paraenses, a qual sucederam-se outras em 1968-69 e 1979-80, o que permitiu constatar o caráter cíclico das epidemiast. Além de Belém, diversos municípios da região leste e baixo Amazonas do Estado do Pará, foram igualmente acometidos por surtos causados pelo $\mathrm{ORO}^{7}$. No biênio 1980-81, pela primeira vez o vírus causou doença fora do território paraense, quando ocorreram epidemias em Manaus e Barcelos, no Estado do Amazonas e Mazagão, no então Território Federal do Amapá8.

(1) Instituto Evandro Chagas-Fundação SESP. Av. Almirante Barroso, 492. Caixa Postal 1128. CEP 66050 Belém, Pará, Brasil.

(2) Instituto Evandro Chagas (Convênio FSESP/CNPq/ORSTOM). Belém, Fará, Brasil. 
VASCONCELOS, P.F. da C.; TRAVASSOS DA ROSA, J.F.S.; GUERREIRO, S.C.; DÉGALLIER, N.; TRAVASSOS

DA ROSA, E.S. \& TRAVASSOS DA ROSA, A.P. de A. - Primeiro registro de epidemias causadas pelo virus Oropouche nos Estados do Maranhão e Goiás, Brasil. Rev. Inst. Med. trop. S. Pqulo, 31(4):271-278, 1989.

O virus ORO mantem-se na natureza através de um ciclo complexo, no qual intervém um ciclo silvestre e outro urbano. As preguiças e os macacos atuam como hospedeiros vertebrados do ORO em ambiente selvático. Aves silvestres têm sido também incriminadas como possíveis hospedeiros. No tocante aos vetores, o ciclo silvestre ainda não foi devidamente esclarecido. Já se obteve um isolamento de cada, a partir de lotes de mosquitos Aedes serratus (Pará) e Coquilletidia venezuelensis (Trinidad), o que os tornam suspeitos de participarem do ciclo de manutenção desse agente. Quanto ao ciclo urbano, o homem apresenta-se como hospedeiro único e a transmissão se faz pelas picadas do maruim Culicoides paraensis e eventualmente do mosquito Culex (Cux.) quinquefasciatus ${ }^{9}$.

$O$ período de incubação é curto, variando em média de 3-6 dias e o quadro clínico é de uma sindrome febril benigna. No entanto, durante a última epidemia registrada em Belém, diversos casos de meningite asséptica foram descritos como decorrentes da infecção pelo ORO. Número significativo de doentes $(60 \%)$ refere episódios recidivantes, em média de 7 a 14 dias após o ataque inicial.

A partir de dezembro de 1987 , numerosos pacientes portadores de doença febril começaram a procurar a unidade sanitária (atendimento médico laboratorial) da Fundação SESP em Porto Franco, MA. Amostras de sangue foram coletadas de inúmeros pacientes e remetidas ao Instituto Evandro Chagas (IEC), onde se conseguiu isolar quatro cepas do vírus ORO. Configurava-se, assim, que a epidemia era causada por esse agente, o que levou os autores a realizarem investigações clínicas e ecoepidemiológicas na vila e arredores do municipio, entre 26 de janeiro e 1 de fevereiro de 1988 . O presente relato descreve, também, dados referentes a epidemia causada pelo mesmo agente, no mesmo período na cidade de Tocantinópolis, GO.

\section{MATERIAL E MÉTODOS}

\begin{abstract}
Áreas de estudo
Porto Franco - O município de Porto Franco está situado às proximidades da BR-010 (Belém-Brasília), da qual dista cerca de $3 \mathrm{~km}$, na região sul do Maranhão, fronteira com Goiás (Figura 1). Aproximadamente 20.000 pessoas constituem a população urbana e rural do município. A agricultura e pecuária são as
\end{abstract}

principals atividades desenvolvidas na área. $O$ periodo de chuva estende-se de dezembro a ju nho e a seca de julho a novembro.

Tocantinópolis - Municipio com população próxima dos 35.000 habitantes, está situada no extremo norte de Goiás, fronteira com o Maranhão e, é separado de Porto Franco, pelo rio Tocantins. Como Porto Franco, a agricultura e a pecuária constituem basicamente as atividades produtivas do Município.

Pacientes - 197 pacientes foram sangrados para estudos sorológicos, 75 dos quais, também para tentativa de isolamento de vírus, por se encontrarem febris no momento da sangria. $80 \%$ dos pacientes foram examinados através de atendimento domiciliar e os demais na unidade sanitária da FSESP em Porto Franco-MA e, postos de saúde, igualmente da FSESP, em distritos localizados na área de abrangência desse município. 45 amostras de sangue de pacientes com suspeita clínica de infecção viral, foram enviadas ao IEC pela unidade mista (atendimento médico-hospitalar e ambulatorial) da FSESP em Tocantinópolis/GO, e inoculados em camundongos recém-nascidos.

Determinação de anticorpos - 197 soros humanos entre doentes em fase aguda e convalescentes e contactos foram testados pela prova de inibição da hemaglutinação (IH) contra a amostra BE AN 19991, protótipo de Belém do vírus ORO. Os métodos utilizados para a prova de IH, preparação do antígeno e tratamento do soro foram descritos anteriormente ${ }^{10,12}$. Os soros positivos nesse teste foram posteriormente testados por MAC ELISA (captura de anticorpos IgM por método imuno-enzimático), apresentando uma positividade (sensibilidade) de $82 \%$ e especificidade de $100 \%$.

Insetos hematófagos: As capturas de insetos foram feitas em dois períodos; diurno, por pessoas voluntárias servindo de isca e usando aspiradores orais, e noturno, efetuada por armadilhas de luz do tipo "CDC light-trap", sempre em locais onde estavam ocorrendo casos da doença. Os insetos capturados, eram colocados em tubos de vidro com rosca, devidamente rotulados e imediatamente imersos em nitrogênio líquido dentro de botijões criobiológicos. No IEC, os artrópodos foram identificados por microscopia óptica, agrupados de acordo com data de coleta, local, espécie, sexo e segundo a presença ou não de sangue.

Isolamento e identificação do vírus - Tentativas de isolamento de vírus foram realizadas 
VASCONCELOS, P.F. da C.; TRAVASSOS DA ROSA, J.F.S.; GUERREIRO, S.C.; DEGALLIER, N.; TRAVASSOS

DA ROSA, E.S. \& TRAVASSOS DA ROSA, A.P. de A. - Primeiro registro de epidemias causadas pelo virus Oropouche nos Estados do Maranhão e Goiás, Brasil. Rev. Inst. Med. trop. S. Paulo, 31(4):271-278, 1989.

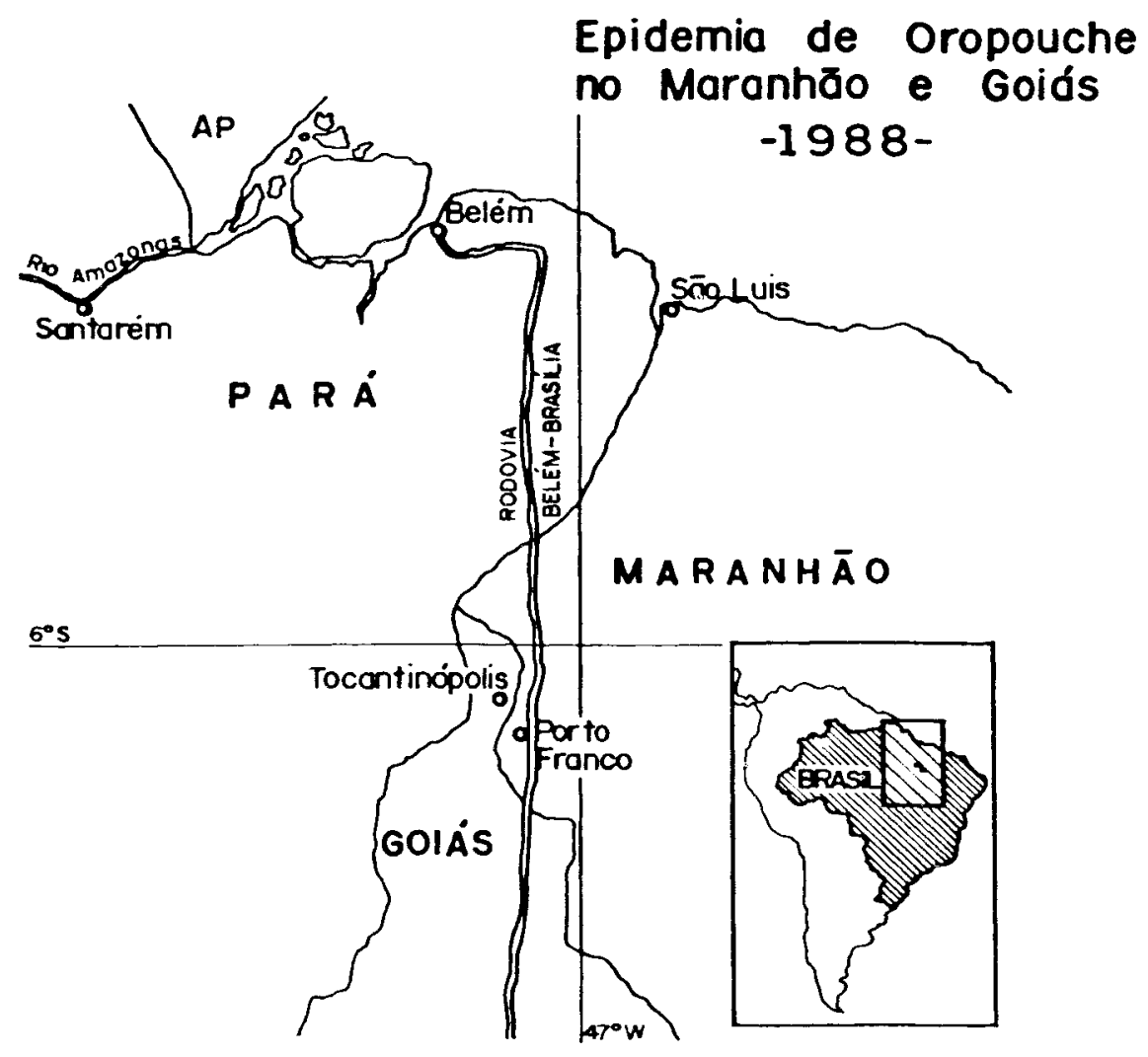

FIGURA 1

através da inoculação de grupos de insetos triturados e do sangue dos pacientes febris - diluídos em uma solução fosfato tamponada contendo $0,75 \%$ de albumina bovina (fração $\mathrm{V}$ ) e antibióticos (penicilina + estreptomicina) - , em camundongos albinos "Swiss" de 2 a 3 dias de idade pela via intra-cerebral, com $0,02 \mathrm{ml} \mathrm{da}$ suspensão. A identificação do vírus foi realizada pelo teste de fixação de complemento de acordo com microtécnica modificada'2, utilizando-se como fonte de antígeno o cérebro de camundongo doente pós-inoculação do vírus e, como fonte de anticorpos fluído ascítico de camundongos hiperimunes ao vírus ORO.

\section{RESULTADOS}

\section{EPIDEMIA DO MARANHÃO}

Estudos humanos - $O$ vírus ORO foi isolado do sangue de $22(29,3 \%)$ dos 75 pacientes com febre que foram examinados em Porto Franco e adjacências. Ressalte-se ainda, a obtenção de 28 reações positivas por MAC ELISA, indicando infecção recente por esse agente.

Manifestações clínicas - As manifestações clinicas foram similares às observadas durante epidemias anteriores, ou sejam: febre - temperatura entre 38 e $39.5^{\circ} \mathrm{C}-$, presente em todos os casos de início brusco, cefaléia, calefrios, 
VASCONCELOS, P.F. da C.; TRAVASSOS DA ROSA, J.F.S.; GUERREIRO, S.C.; DÉGALLIER, N.; TRAVASSOS DA ROSA, E.S. \& TRAVASSOS DA ROSA, A.P. de A. -- Primeiro registro de epidemias causadas pelo vírus Oropouche nos Estados do Maranhão e Goiás, Brasil. Rev. Inst. Med. trop. S. Paulo, 31(4):271-278, 1989.

TABELA 1

Sintomas apresentados por 50 pacientes com febre por Oropouche dos quais se obteve história clínica em Porto Pranco/MA, 1988

\begin{tabular}{lcc}
\hline Sintomas & $\begin{array}{c}\text { No de } \\
\text { pacientes }\end{array}$ & $\begin{array}{c}\% \text { de } \\
\text { frequência }\end{array}$ \\
\hline Febre & 50 & 100 \\
Cefaléia & 44 & 88 \\
Mialgias & 38 & 76 \\
Artralgias & 32 & 64 \\
Fotofobia & 29 & 58 \\
Calcfrios & 27 & 54 \\
Tontura & 21 & 42 \\
Náuseas & 12 & 24 \\
Vômitos & 12 & 24 \\
Anorexia & 7 & 14 \\
Dor retro-ocular & 7 & 14 \\
Adinamia & 3 & 6 \\
\hline
\end{tabular}

mialgias, artralgias e tontura foram os sintomas mais frequentemente encontrados na maioria dos pacientes; fotofobia e dor retro-ocular comumente foram também relatadas. Ocorreram ainda outros sintomas, tais como náuseas, vômitos, anorexia e adinamia (Tabela 1). Entre os casos estudados não evidenciou-se a presença de exantema bem como sintomas ou sinais meningeos.

Como em outras epidemias, observou-se nesta, elevada freqüência de recidivas $(56 \%)$, nas quais os pacientes, cerca de 1-2 semanas após o ataque inicial, apresentaram os mesmos sintomas ou apenas, febre, cefaléia e mialgias. Exames complementares não foram realizados devido a precariedade do local, que não dispõe de laboratório de patologia clínica.

A distribuição por idade e sexo da soropositividade apresentou predomínio na faixa etária de 10 a 19 anos (81,2\% entre os homens) e no grupo de 50 anos ou mais $(77,7 \%$ no sexo masculino) e menor freqüência no grupo de 40-49 $(38,4 \%$ para os homens e $42,8 \%$ para as mulheres). Esta flutuação poderia ser atribuida ao caráter dirigido (busca ativa de casos) e não aleatório. A análise estatística $\left(\mathrm{x}^{2} \mathrm{GL}=11,98\right.$ p $<0,05$ ) não mostrou significância (Tabela 2).

Os títulos de viremia em camundongos recém-nascidos inoculados por via intra cerebral foram de 1,3 a 4,5 log LD50/0,02ml. Em relação à prevalência de anticorpos contra o vírus ORO, mediante os testes IH e MAC ELI$\mathrm{SA}$, obteve-se positividade de $53,8 \%$ (106 posi-
TABELA 2

Distribuição por sexo e idade dos pacientes com soros testados e positivos para febre do Oropouche colhidos em Porto Franco/MA, 1988.

\begin{tabular}{rcrcc}
\hline Idade & Sexo & Testados & Positivos & $\%$ Positividade \\
\hline \multirow{2}{*}{$0-09$} & M & 12 & 6 & 50,0 \\
& F & 7 & 4 & 57,1 \\
$10-19$ & M & 32 & 26 & 81.2 \\
& F & 38 & 27 & 71,0 \\
$20-29$ & M & 20 & 13 & 65,0 \\
& F & 20 & 12 & 60,0 \\
\multirow{2}{*}{$40-39$} & M & 23 & 15 & 65,2 \\
& F & 6 & 3 & 50,0 \\
& M & 13 & 5 & $38: 4$ \\
50 & F & 7 & 3 & 42,8 \\
& M & 9 & 7 & 77.7 \\
& F & 10 & 7 & 70,0 \\
\hline \multirow{2}{*}{ Total } & M & 109 & 72 & 66,1 \\
& F & 88 & 56 & 63,6 \\
\hline
\end{tabular}

tivos de 197 soros examinados) simultaneamente nos dois testes. Entre estes, nove são de contactos de alguns casos que negaram ter apresentado febre ou outros sintomas por pelo menos 30 dias antes da colheita da amostra. Infelizmente, não foi possivel realizar inquérito soroepidemiológico randomizado pelo curto periodo de tempo disponivel para a execução do trabalho.

Insetos hematófagos: Foram capturadas 5940 fêmeas de dípteros hematófagos (Tabela 3), sendo 2253 Culicidae, 3626 Ceratopogonidae 61 de Simulidae. Foram inoculadas 5936 fêmeas (137 lotes), sendo 2251 Culicidae (97 lo(es), 3624 de Ceratopogonidae (39 lotes) e 61 de Simulidae (1 lote). Conseguiu-se o isolamento de amostra de ORO, a partir de um lote de Culicoides paraensis.

\section{EPIDEMIA DE GOIÁS}

Foram isoladas dez amostras de virus, que por FC' mostraram-se idênticas ao vírus ORO. Testes sorológicos, por meio da reação de $\mathrm{IH}$, foram realizados com os soros, nos quais encontramos sete reações em títulos compativeis com infecção recente $(1: 80)$, confirmados posteriormente por MAC ELISA. Como ocorreu no Maranhão, os sintomas predominantes fo ram febre, cefaléia, calefrios, mialgias e artral gias que duraram em média de 3-5 dias, findos os quais, a convalescença não revelou seqüelas. 
VASCONCELOS, P.F. da C.; TRAVASSOS DA ROSA, J.F.S.; GUERREIRO, S.C.; DEGALLIER, N.; TRAVASSOS DA ROSA, E.S. \& TRAVASSOS DA ROSA, A.P. de A. - Primeiro registro de epidemias causadas pelo vírus Oropouche nos Estados do Maranhão e Goiás, Brasil. Rev. Inst. Med. trop. S. Paulo, 31(4):271-278, 1989.

TABLLA 3

Fiemcas de dípteros hematófagos capturadas em Porto Franco/MA, 1988.

Espécies

Capturadas

Inoculadas

Nọ lotes

\section{CULICIDAE}

Anophelinae

$$
\begin{aligned}
& \text { Anopheles (Anopheles) sp. } \\
& \text { An. (Nyssorhynchus) nuneztovari } \\
& \text { An. (Nys.) triannulatus }
\end{aligned}
$$

1
20
7

Culicinas

Aedini

Aedes (Ochlerotatus) scapularis

Psorophora (Grabhamia) cingulata

Ps. (Janthinosoma) ferox

Culicini

$$
\begin{aligned}
& \text { Culex sp. } \\
& \text { Cx. }(\text { Carrolia }) \text { sp. } \\
& \text { Cx. }(\text { Culex }) \text { corniger } \\
& \text { Cx. }(\text { Cux. }) \text { coronator } \\
& \text { Cx. }(\text { Cux. }) \text { coronator }+C x .(\text { Mel. }) \text { sp. } \\
& \text { Cx. }(\text { Cux. declarator } \\
& \text { Cx. }(\text { Cux. }) \text { quinquefasciatus }
\end{aligned}
$$

Mansoniini

Cq. (Rhy.) sp. +Ma. (Man.) titillans

Sabethini

Limatus sp.

Sabethes (Sabethoides) glaucodaemon

wyeomyia sp.

Uranotaeniini

Uranotaenia sp.

TOTAL CULICIDAF

\section{CERATOPOGONIDAE}

Culicoides (Oecacta) paraensis

Ceratopogonidae sp. No. 1

Ceratopogonidae sp. No. 2

TOTAL CIRATOPOGONIDAE:

SIMULIDAE:

Simulium $s p$

TOTAL SIMULIDAE:

TOTAL GERAL

\section{DISCUSSÃO}

Este é o primeiro registro de epidemias causadas pelo virus ORO nos Estados do Maranhão e Goiás. Até 1980, várias epidemias haviam ocorrido na região Amazônica, particularmente no Estado do Pará. A partir de então, três epidemias foram detectadas fora dos limites paraen- ses, sendo duas no Estado do Amazonas (Manaus e Barcelos) e uma no então Território Federal do Amapá (Mazagão).

No episódio em pauta, a proximidade das duas cidades Porto Franco e Tocantinópolis (Figura 1), foi fundamental para a disseminação da doença.

Vale ressaltar que o virus ORO é o arbovírus 
VASCONCELOS, P.F. da C.; TRAVASSOS DA ROSA, J.F.S.; GUERREIRO, S.C.; DÉGALLIER, N.; TRAVASSOS DA ROSA, E.S. \& TRAVASSOS DA ROSA, A.P. de A. - Primeiro registro de epidemias causadas pelo vírus Oropouche nos Estados do Maranhão e Goiás, Brasil. Rev. Inst. Med. trop. S. Paulo, 31(4):271-278, 1989.

que mais infecções tem causado no homem amazônico. Estimativas conservadoras indicam que até 1980 mais de 263.000 pessoas foram acometidas pela febre do ORO'1.

Embora seja relativamente fácil isolar o virus do sangue de pacientes na fase aguda, o mesmo não ocorre em relação aos artrópodes. Até hoje, de milhares de insetos capturados no decorrer das inúmeras epidemias pregressas, só conseguiu-se isolar 11 amostras do vírus a partir de lotes do maruim Culicoides paraensis e três dos lotes do mosquito Culex (Culex) quinquefasciatus. Faz-se necessário estudos para determinar se esse fenômeno é devido a baixa susceptibilidade dos insetos ao vírus ORO, ou se somente uma pequena fração da população desses insetos tem habilidade para transmitir o agente ${ }^{6}$. As taxas de infecção real dos vetores (IIRV), estimadas segundo o método de WAL TER el al. ${ }^{1+}$, foram as seguintes:

\section{Culicoides paraensis:}

- Mojuí dos Campos (Santarém, PA), 24/2 $-10 / 4 / 75$ TIRV $=0,0123 \pm 0,008 \%$

-- Alter do (hão (Santatém, PA), 22/8/1975 $-15 / 1 / 1976$ TIRV $=0,0325 \pm 0,\left(1230_{0}\right.$

-- Manaus, Amazonas 6 - 13/12/1980 TIRV $=0,0172 \pm 0,017 \%$

- Porto Franco, MA 27/1 - 7/2/1988 TIRV $=0,0278 \pm 0,027 \%$

\section{Culex quinquefasciatus:}

$$
\begin{aligned}
& \text { - Belém, PA, 26/3 - 20/6/I968 IIRV } \\
& 0,0110 \pm 0,0070 \%
\end{aligned}
$$

Esses valores correspondem de 2 a 5 vezes os valores da taxa de infecção mínima calculada a partir de todo material colhido ao longo das numerosas epidemias ${ }^{15,16}$. Além disso, o teste de comparação de médias ${ }^{14,17}$, realizado entre esses valores, dois a dois, não permitiu evidenciar nenhuma diferença significativa ao limiar de $5 \%$.

Esta análise sugeriu que, ao contrário das conclusões apresentadas pelos autores ${ }^{15,16}$, ainda não pode ser eliminada a possibilidade do Cx. quinquefasciatus desempenhar o papel de vetor da mesma ordem que o do C. paraensis.
A baixa taxa de isolamentos pode ser devida à inoculação de espécimes engurgitados contendo sangue de humanos com anticorpos para o ORO.

Em epidemias anteriormente estudadas nada foi feito em relação a pesquisa de IgM por meio dos ensaios imuno-enzimáticos (MAC ELISA). Particularmente, no est udo em pauta, a realização concomitante das provas IH e MAC ELISA permitiu distinguir os casos de infecção recente $(\mathrm{N}=106)$ dos casos de infecção passada. Nesse sentido, obtivemos por $1 \mathrm{H}, 128$ amostras positivas, enquanto que pelo MAC ELISA somente em 106 soros foi detectada $\operatorname{IgM}$, configurando infecção atual ou recente.

Vale ressaltar que embora todas as tentativas tenham sido feitas objetivando isolar o ORO de pacientes cujos soros apresentavam títulos de anticorpos IH entre 1:20 e 1:80 e MAC ELISA positivo, nenhuma amostra foi isolada. Ainda, no que diz respeito a sorologia, foi observado que 19 pessoas possuiam anticorpos $\mathrm{IH}$ para o ORO porém, mantiveram-se repetidamente negativas pelo MAC ELISA. O contrário não foi observado, isto é, todos os soros positivos para IgM por MAC ELISA o foram também por IH.

Embora haja evidências de que a epidemia provavelmente tenha iniciado em meados do mês de dezembro de 1987 , somente no final de janeiro é que foi possivel realizar o estudo em pauta, em virtude dos primeiros materiais recebidos pelo IEC, terem chegado ao laboratório somente na 2 a semana de janeiro de 1988 . Sabese, entretanto, que a epidemia cursou até março de 1988. Convém lembrar que, antes do diagnóstico virológico ser efetuado, a suspeita clínica dos médicos da FSESP e Secretaria de Saúde do Maranhão era de febre do dengue.

Um fato que se nos afigura freqüentemente, e que ainda não está bem entendido, é a recurrência dos sintomas uma a duas semanas após o ataque inicial. Tentativas de recuperar o vírus do sangue dos pacientes, nesses episódios secundários, sempre foram infrutíferas, mormente, considerando que o quadro clinico é, na maioria das vezes, idêntico ao do primeiro ataque. No surto em estudo as recidivas corresponderam a $56 \%$ dos casos positivos, o que está de acordo com a literatura, onde tem-se observado em média o percentual de $60 \%$. É possível, que este fato seja decorrente de manifestações de hipersensibilidade a imunocomplexos circulantes, posto que, a recidiva coincide com o píco da resposta imune. 
VASCONCELOS, P.F. da C.; TRAVASSOS DA ROSA, J.F.S.; GUERREIRO, S.C.; DÉGALLIER, N.; TRAVASSOS DA ROSA, E.S. \& TRAVASSOS DA ROSA, A.P. de A. - Primeiro registro de epidemias causadas pelo vírus Oropouche nos Estados do Maranhão e Goiás, Brasil. Rev. Inst. Med. trop. S. Paulo, 31(4):271-278, 1989.

\section{SUMMARY}

\section{Epidemic outbreaks of Oropouche virus in the Maranhão and Goiás States, Brazil.}

The authors describe the occurrence of outbreaks caused by Oropouche virus $(\mathrm{ORO})$ in the states of Maranhão and Goiás, Brazil in 1988. 36 strains of the virus were obtained from the intracerebral inoculation of the blood of 120 patients into $2-3$ day-old infant mice. The illness was characterized by headache, fever, pain in the muscles, joints and back, photophobia, retrobulbar pain, nausea and dizziness. 128 of 197 people examined in Porto Franco, MA, had hemagglutination-inhibiting antibodies to the agent, while 106 of them had IgM antibodies by MAC ELISA test. All age groups were infected, although the incidence was higher among who had 10 to 19 years old. There was no difference, in relation to sex infections. Recurrence of symptoms was reported in $56 \%$ of sick people. Mice inoculated with 3624 Culicoides paraensis (Ceratopogonidae) and 1970 Culex (Cux.) quinquefasciatus (Culicidae) collected in Porto Franco resulted in one single isolation of ORO virus, from the Culicoides.

These are the first confirmed cases of ORO infection in Maranhão and Goiás states.

\section{AGRADECIMENTOS}

Agradecemos ao Dr. Ednaldo Santos, Chefe da Unidade Sanitária de Porto Franco da FSESP pela inestimável colaboração prestada ao nosso trabalho. Extensivo, igualmente, ao Dr. Cacildo Teodoro Assunção Filho, SubSecretário de Saúde do Maranhão e as equipes da FSESP e Secretaria de Saúde pelo apoio logístico, cooperação e amizade demonstradas.

Particularmente externamos nossa gratidão aos servidores do IEC que contribuiram para o exito deste trabalho: Basílio Silva Buna, Francisco Corrêa Castro, Hamilton Antonio de Oliveira Monteiro, Osvaldo Vaz da Silva, Iveraldo Ferreira da Silva, Antonio da Silva Santos, Luiz Roberto Oliveira da Costa, Maria Rute Castro de Freitas, Ivan Cintra Alves, Armando de Sousa Pereira e Maxwell Furtado de Lima. Ao Dr. Carlos Osanai pela revisão do texto e a Srta. Telma Vasconcelos pelos serviços datilográficos.

\section{REFERÊNCIAS BIBLIOGRÁFICAS}

1. CASALS, J. - The arthropod-borne group of animai viruses. Trans. N.Y. Acad. Sci. S. 2, 19:219-235, 1957.

2. BISHOP, D.H.L. \& SHOPE, R.E. - Bunyaviridae. In: FRAENKEL-CONRAT, H. \& WAGNER, R.R. ed. Comprenhensive virology. New York, Plentm Press, 1979 p.1-156.

3. KARABATSOS, N., ed. -- International Catalogue of Arboviruses, including certain other viruses of verte brates. 3rd. ed. San Antonio, Texas, The American Society of Tropical Medicine and Hygiene, 1985.

4. PINHEIRO, F.P. - Febre do Oropouche. J. bras. Med., 44(4):46-62, 1983

5. PINHEIRO, F.P.; PINHEIRO, M.; BENSABATH G.; CAUSEY, O.R. \& SHOPE, R.E. - Epidemia do vírus Oropouche em Belém. Rev. Serv. Saúde públ. (Rio de J.), 12(1): 15-23, 1962.

6. PINHEIRO, F.P.; TRAVASSOS DA ROSA, A.P.A.; TRAVASSOS DA ROSA, J.F.S.; ISHAK, R.; FREI TAS, R.B.; GOMES, M.L.C.; LE DUC, J.W.\& OLI VA, O.F.P. - Oropouche virus. I. A review of clinical, epidemiological, and ecological findings. Amer. J. trop. Med. Hyg., 30:149-160, 1981.

7. FREITAS, R.B.; PINHEIRO, F.P.; SANTOS, M.A.V.; TRAVASSOS DA ROSA, A.P.A.; TRA VASSOS DA ROSA, J.F.S. \& FREITAS, E.N - Epidemia de vírus Oropouche no Leste do Estado do Pará 1979. Rev. Fund. SESP. (Rio de J.), 25(2):59-72, 1980)

8. BORBOREMA, C.A.T.; PINHEIRO, F.P.; Al.BLQUERQUE, B.C.; TRAVASSOS DA ROSA, A.P.A.; TRAVASSOS DA ROSA, J.F.S. \& DOURADO, H.Y. - Primeiro registro de epidemias causadas pelo virus Oropouche no Estado do Amazonas. Rev. Inst. Med. trop. S. Paulo, 24:132-139, 1982.

9. PINHEIRO, F.P.; ROCHA, A.G.; FREITAS, R.B OHANA, B.A.; TRAVASSOS DA ROSA, A.P.A. ROGERIO, J.S. \& LINHARES, A.C. - Meningite associada as infecçoes por virus Oropouche. Rev. Inst. Med. trop. S. Panlo, 24:246-251, 1982.

10. CLARKE, D.H. \& CASALS, J. - Techniques for hemagglutination-inhibition test with arthropod-borne viruses. Amer. J. trop. Med. Hyg., 7:561-573, 1958.

11. SHOPE, R.E. - The use of a nicrohemagglutinationinhibition test to follow antibody response after arthropod-borne virus infection in a community of forest aninals. An. Microbiol. (Rio de J.), 11 (Parte A): $167-171,1963$.

12. FULTON, F. \& DUMBELL, K.R. - The serotogical comparison of strains of influenza virus. J. gen. Microbiol., 3:97-111, 1946.

13. PINHEIRO, F.P.; TRAVASSOS DA ROSA, A.P.A.; FREITAS, R.B.; TRAVASSOS DA ROSA, J.F.S. \& VASCONCELOS, P.F.C. - Arboviroses. Aspectos clínico-epidemiológicos. In: Instituto Evandro Chagas, 50 anos de contribuição às ciências biológicas e à medicina tropical. Belém, Fundação Serviços de Saúde Pública, 1986. v.1, p.375-408.

14. WALTER, S.D.; HILDRETH, S.W. \& BEATY, B.J - Estimation of infection rates in populations of organisms using pools of variable size. Amer. J. Epidem., 112:124-128, 1980.

15. PINHEIRO, F.P.; HOCH, A.L.; GOMES, M.I.C. \& ROBERTS, D.R. - Oropouche virus. IV. Laboralory Iransmission by Culicoides paraensis. Amer. J. trop. Med. Hyg., 30:172-176, 1981. 
VASCONCELOS, P.F. da C.; TRAVASSOS DA ROSA, J.F.S.; GUERREIRO, S.C.; DÉGALLIER, N.; TRAVASSOS DA ROSA, E.S. \& TRAVASSOS DA ROSA, A.P. de A. - Primeiro registro de epidemias causadas pelo vírus Oropouche nos Estados do Maranhão e Goiás, Brasil. Rev. Inst. Med. trop. S. Paulo, 31(4):271-278, 1989.

16. HOCH, A.L.; PINHEIRO, F.P.; ROBERTS, D.R. \& GOMES, M.L.C. - El virus Oropouche. Transinision en el laboratorio por Culex quinquefasciatus. Bol. Ofic, sanit. panamer., 103:106-112, 1987.

17. BERQUO, E.S.; SOUZA, J.M.P. \& GOTLIEB. S.L.D. - Bioestatística. Sào Paulo, E.P.U., 1981 p.233-236.
18. JOHNSON, B.K. \& VARMA, M.G.R. - Infection of the mosquito Aedes aegypti with infectious West Nile virus-antibody complexes. Trans. roy. Soc. trop. Med. Hyg., 69:336-341, 1975.

Recebido para publicação em $08 / 12 / 1988$ 